\title{
Investigation of the microstructure and X-ray spectral microanalysis of powder material obtained from waste of the KNT16 brand tungsten-free hard alloy
}

\author{
B.N. Sabel'nikov ${ }^{1, *}$, A.E. Ageeva ${ }^{2}$, V.O. Podanov ${ }^{1}$, M.S. Korolev ${ }^{1}$ \\ ${ }^{1}$ Southwest State University, 305040 Kursk, Russian Federation \\ ${ }^{2}$ Secondary school No. 53, 305018 Kursk, Russian Federation
}

\begin{abstract}
This article presents the results of X-ray spectral microanalysis and the study of the microstructure of an experimental electroerosive powder material obtained from waste of a tungsten-free hard alloy grade KNT16.
\end{abstract}

\section{Introduction}

The first appearance of tungsten-free hard alloys (TFHA) was noted in the early 30s of the last century, but they did not receive proper attention and, accordingly, spread due to insufficient strength and were replaced by tungsten-containing alloys of such groups as VK, TK and TTK. However, the rapidly developing shortage of expensive tungsten pushed in the late $50 \mathrm{~s}$ to return to the search for hard alloys, the composition of which does not include tungsten $[1,2]$.

Since 1973, our country has been producing TFHA based on titanium carbide (MNT-A2 and TN group alloys), titanium carbonitride (KNT group), titanium and niobium complex carbide (TM group).

Titanium carbide and carbonitride are not so scarce, the process of their production is quite simple, and in terms of hardness they even surpass tungsten carbide, their scaling resistance is higher, and the presence of a thin oxide film that forms on the surface of products acts during the operation of the tool at high temperatures as solid lubricant. Due to this property, TFHA have a fairly low coefficient of friction and resist wear rather well [3].

In addition, tungsten-free hard alloys also have a number of advantages over tungstencontaining hard alloys in such parameters as hardness, scale resistance, wear resistance at high temperatures. Due to the slight tendency to seizure (the setting temperature of TFHA with steel in vacuum is about $200^{\circ} \mathrm{C}$ higher than for alloys of the TK group), TFHA is recommended to be used in the processing of carbon and alloy steels. So, for processing steel 45, the most promising alloys are KNT16, KNT20, KNT30; for processing steel ShH15 - KNT16 [4-6].

\footnotetext{
* Corresponding author: sabelnikovboris1@mail.ru
} 
In connection with the growing demand for TFHA in industry, there is an acute problem of processing their waste with the possibility of reuse.

Certainly, considerable attention should be paid to the method of processing almost any material that is a conductor of electric current, including waste of TFHA, which stands out among other methods with relatively low energy consumption and environmental friendliness of the process - the process of electroerosive dispersion (EED) $[7,8]$.

\section{Materials and Methods}

To carry out the planned studies, wastes of a tungsten-free hard alloy grade KNT16 in the form of spent hard-alloy plates were used. Ethyl alcohol was used as the working fluid.

The reactor, with the working fluid in it, was filled with hard alloy waste. In this case, the process of obtaining powder materials (PM) took place with the following operating parameters of the installation:

- the range of the pulse repetition rate is $95-105 \mathrm{~Hz}$;

- voltage range on the electrodes 195-205 V;

- the capacity indicator of the discharge capacitors is $25.5 \mu \mathrm{F}$.

The resulting PM was investigated in various ways.

By the method of scanning electron microscopy using an electron-ion scanning microscope "Quanta 600 FEG" (Fig. 1), a study of the microstructure of the KNT16 powder material (charge) was carried out.

Quanta 600 FEG - electron-ion scanning microscope with an electron-beam column equipped with a tungsten cathode, accelerating voltage from $200 \mathrm{eV}$ to $30 \mathrm{kV}$, resolution (at optimal WD) $3.5 \mathrm{~nm}$ at $35 \mathrm{kV} ; 3.5 \mathrm{~nm}$ at $30 \mathrm{kV}$ in natural mode; $<15 \mathrm{~nm}$ at $1 \mathrm{kV}$ in low vacuum mode.

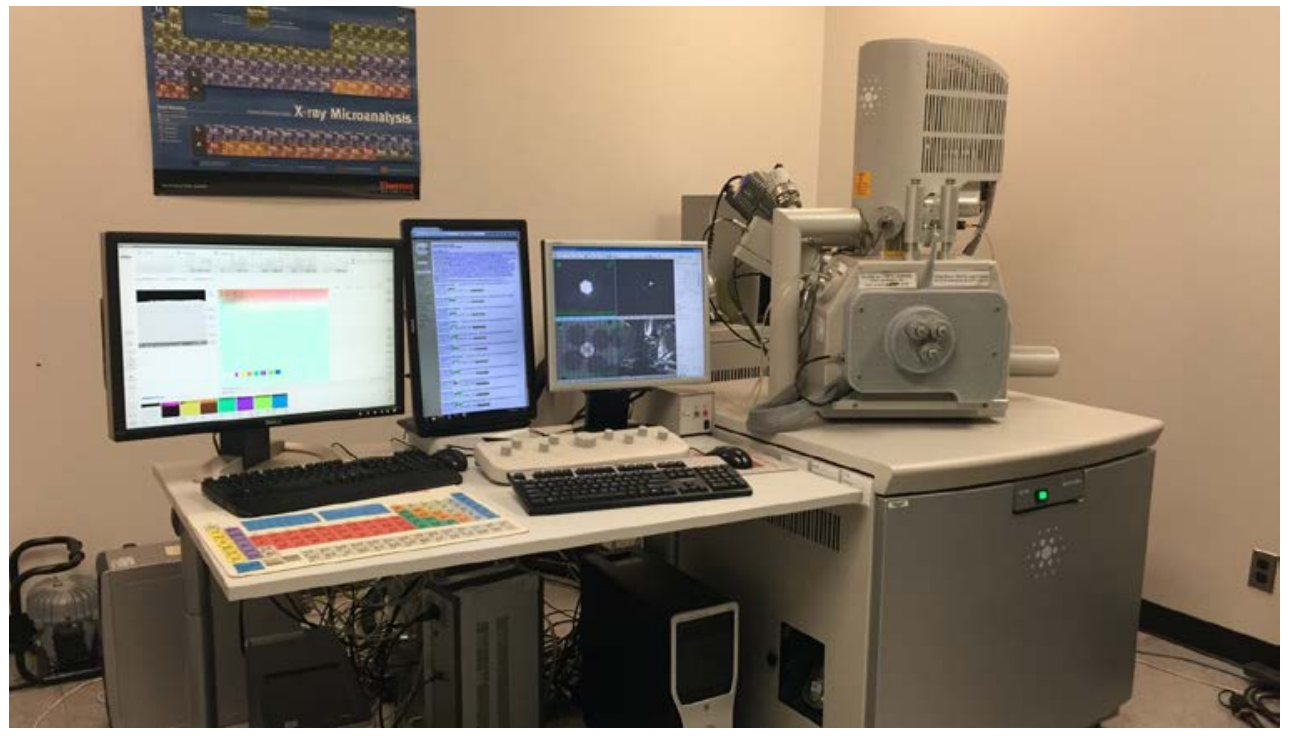

Fig. 1. Electron-ion scanning microscope "Quanta 600 FEG" with energy-dispersive X-ray analyzer from EDAX

\section{Results}

Fig. 2. presents the results of a study of the microstructure of a powder material obtained from waste TFHA grade KNT16. 


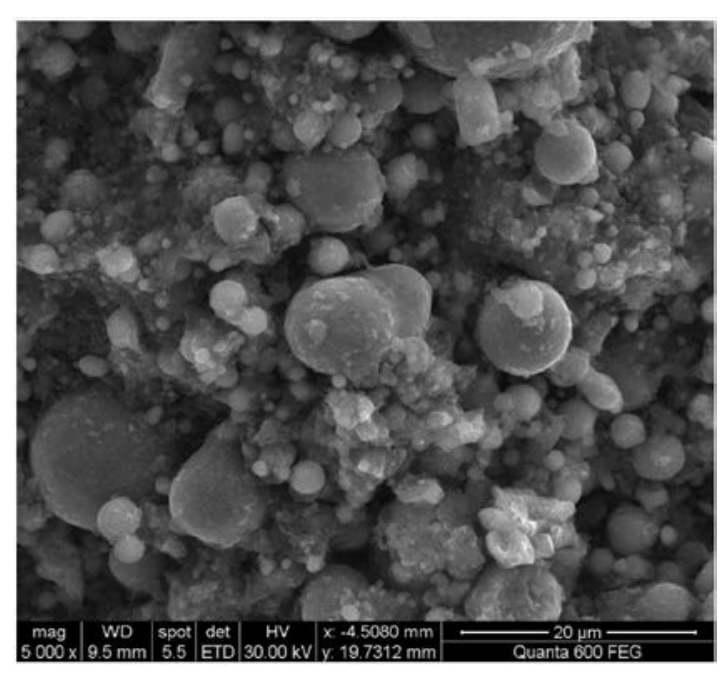

Fig. 2. Microstructure of the charge obtained by the EED method of waste TFHA grade KNT16

The powder material obtained in an experimental installation by the EED method from waste TFHA grade KNT16, for the most part, consists of particles of regular spherical shape (or elliptical), with a small proportion of inclusions of irregular shape (conglomerates).

Fig. 3 shows an X-ray spectral microanalysis of the experimental powder material TFHA grade KNT16.

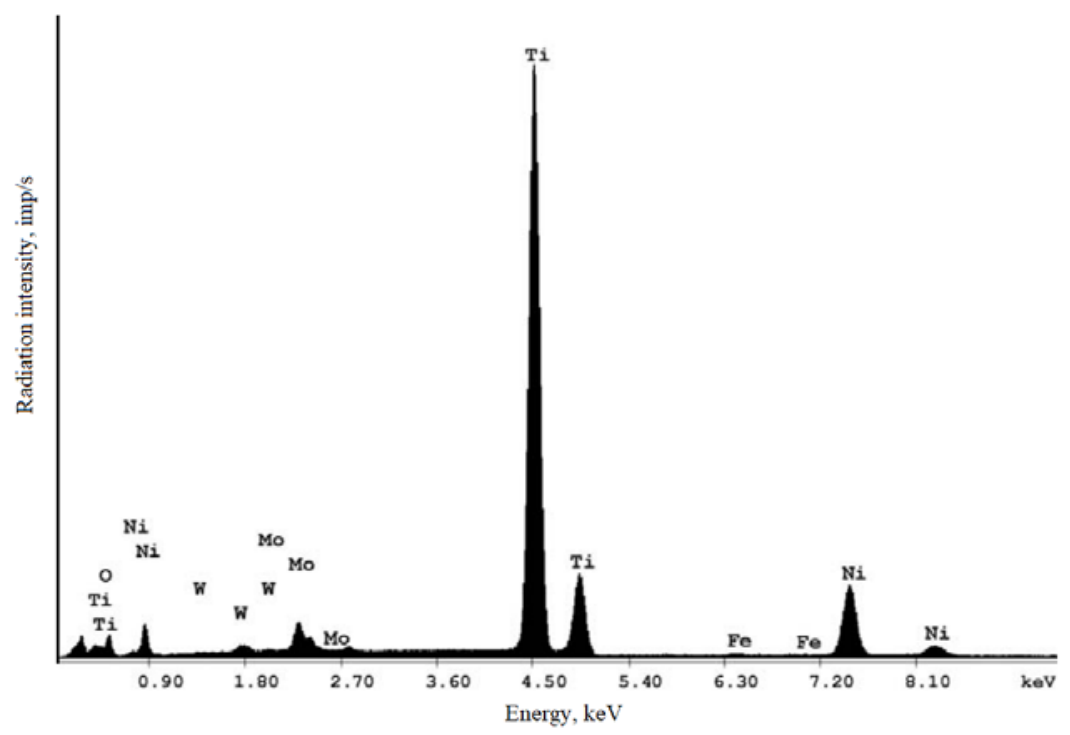

Fig. 3. X-ray spectral microanalysis of the experimental powder material TFHA grade KNT16

Table 1 shows the elemental composition of the obtained PM (charge) of tungsten-free hard alloy KNT16. 
Table 1. Elemental composition of the obtained PM (charge) of tungsten-free hard alloy grade KNT16

\begin{tabular}{|c|c|c|}
\hline Element & Wt, $\%$ & At, $\%$ \\
\hline $\mathrm{O}$ & 12.22 & 31.40 \\
\hline $\mathrm{W}$ & 3.08 & 0.69 \\
\hline $\mathrm{Mo}$ & 5.78 & 3.03 \\
\hline $\mathrm{Ti}$ & 60.78 & 52.17 \\
\hline $\mathrm{Fe}$ & 0.20 & 0.15 \\
\hline $\mathrm{Ni}$ & 17.94 & 12.56 \\
\hline Total & 100 & 100 \\
\hline
\end{tabular}

\section{Conclusion}

By scanning electron microscopy using an electron-ion scanning microscope "Quanta 600 FEG", it was found that the powder material obtained in an experimental setup by the EED method from waste TFHA grade KNT16, for the most part, consists of particles of regular spherical shape (or elliptical), with a small proportion of irregularly shaped inclusions (conglomerates).

According to the results of X-ray spectral microanalysis data, it was found that the main elements in PM TFHA, obtained by the method of electroerosive dispersion of KNT16 alloy wastes in ethyl alcohol, are titanium (Ti), nickel (Ni), oxygen $(\mathrm{O})$ and molybdenum (Mo).

\section{References}

1. A. Pereverzev, E. Ageev, MATEC Web of Conf., 298, 00037 (2019)

2. E.V. Ageeva, E.V. Ageev, N.M. Horyakova, Russ. Eng. Res., 35, 33-35 (2015)

3. E.V. Ageev Patent 2449859, Russian Federation, C2, B22F9 / 14. Installation for producing nanodispersed powders from conductive materials, applicant and patent holder Southwestern State University. - No. 2010104316/02; application 02/08/2010; publ. 05/10/2012, 4 .

4. V. Serebrovsky, B. Sabel'nikov, MATEC Web of Conf., 315, 01002 (2020)

5. E.V. Ageev, A.Yu. Altukhov, S.V. Khardikov, S.S. Gulidin, A.N. Novikov, J. NanoElectron. Phys., 7, 04080 (2015)

6. E.V. Ageev, S.V. Khardikov, E.A. Vorobyev, A.A. Sysoev, MATEC Web of Conf., 298, 00127 (2019)

7. E.V. Ageev, V.L. Selyutin, S.V. Pikalov, MATEC Web of Conf., 315, 01004 (2020)

8. R.A. Latypov, E.V. Ageeva, G.R. Latypova, MATEC Web of Conf., 298, 00125 (2019) 